\title{
(1) Some Topics Concerning Etiology and Clinical Features of Idiopathic Cardiomyopathy
}

\author{
Hiromitsu Tanaka, MD
}

\author{
The First Department of Internal Medicine, Faculty of Medicine, Kagoshima \\ University, Usuki-cho 1208-1, Kagoshima, 890, Japan
}

In 1949, Evans ${ }^{1)}$ reported a number of patients with familial occurrence of cardiomegaly associated with heart failure, arrhythmias and sudden death, and designated this condition as familial cardiomegaly. Since then, a number of reports of familial cardiomyopathy have appeared in the literature. Reviewing of these reports ${ }^{2-6}$ shows that there are a variety of clinical and pathological features in the cases of familial cardiomyopathy. They include hypertrophic cardiomypathy with or without obstruction, congestive cardiomyopathy, heart block and sick sinus syndrome.

The following case seems to be interesting because the patient had medial thickening of the small coronary artery in the myocardium which is the another aspect of various characteristics of familial cardiomyopathy ${ }^{7}$.

Case report. A 27-year-old barber was admitted to our hospital complaining of dyspnea and cough. He complained of dyspnea, precordial pain and cold sweat on exertion since his early childhood. In the family of this patient, seven members extending to three generations died suddenly or died from heart disease. His parents were first cousins. The EGG on admission showed biatrial hypertrophy and complete right bundle branch block with abnormal left axis deviation. Chest X-ray photo revealed pulmonary congestion and enlarged heart. He died from progressive heart failure refractory to the treatment. Autopsy findings: The heart was $570 \mathrm{gm}$ in weight. On cross section of the heart, there was whitish discoloration of fibrosis. Microscopic examination showed widespread fibrosis in the left ventricle, interventricular septum and right ventricle. Throughout the left ventricle and interventricular septum, there was marked medial thickening in small and medium-sized arteries with occasional thrombus formation. Reviewing the literature of familial cardiomyopathy of both Japanese and foreign reports including 29 autopsy cases showed that 44 percent of the cases had small coronary artery disease. The causal relationship between small coronary artery disease and myocardial fibrosis is an interesting problem but is yet to be settled.

Genetic analysis of idiopathic cardiomyopathy has been tried only recently. In 1971, Emanuel et al $^{8}$ ) examined 617 firstdegree relatives of 97 patients with idiopathic cardiomyopathy. The results of analysis suggested that the disease had both dominant and recessive mode of transmission. In 1973, Clark et al ${ }^{9)}$ examined 159 first-degree relatives of 30 index cases of asymmetric septal hypertrophy which they used as a disease marker of idiopathic hypertrophic subaortic stenosis. They concluded that most patients with asymmetric septal hypertrophy had genetic defect that was transmitted as an autosomal dominant trait with a high degree of penetrance. Recently, Yamaguchi et $\mathrm{al}^{10)}$ examined first-degree relatives of 65 propositi of idiopathic cardiomyopathy of 4 types. They concluded (1) that asymmetric septal hypertrophy with obstruction had an autosomal dominant mode of inheritance, (2) that the nonobstructive type was composed of several heterogenous entities, such as autosomal dominant type, autosomal 
Table 1. Light microscopic findings of myocardium in $\mathrm{KK}$ mice.

\begin{tabular}{ccccccccc}
\hline Group & $\begin{array}{c}\text { Age } \\
\text { (weeks) }\end{array}$ & $\begin{array}{c}\text { No Urine Hyper- } \\
\text { sugar glycemia }\end{array}$ & $\begin{array}{c}\text { Myocardial } \\
\text { degeneration }\end{array}$ & $\begin{array}{c}\text { Myocardial } \\
\text { fibrosis }\end{array}$ & $\begin{array}{c}\text { Calcification } \\
\text { Pericardium Myocardium }\end{array}$ \\
\hline \multirow{2}{*}{$\mathrm{KK}-1$} & 4 & 7 & - & - & 0 & 0 & 0 & 0 \\
$\mathrm{KK}-2$ & $11-13$ & 12 & - & - & $5 / 12$ & $5 / 12$ & $6 / 12$ & $5 / 12$ \\
$\mathrm{KK}-3$ & $20-30$ & 6 & + & + & $6 / 6$ & $6 / 6$ & $6 / 6$ & $6 / 6$ \\
$\mathrm{KK}-4$ & $26-46$ & 5 & ++ & ++ & $5 / 5$ & $5 / 5$ & $5 / 5$ & $5 / 5$ \\
\hline
\end{tabular}

recessive type, and non-genetic or polygenic type, and (3) that congestivecardiomyopathy was due to an autosomal recessive mutant gene.Based on these results, it may be reaso nable to think that the genetic factor plays a major role in the etiology of idiopathic cardiomyopathy when any suspected etiologies such as viral infection, alcoholism and peripartal state are excluded.

The development of animal model has contributed very much to clinical medicine. $\mathrm{We}^{11,12)}$ found that the $\mathrm{KK}$ mouse can be used as a disease model of spontaneous cardiomyopathy. The $\mathrm{KK}$ mouse is an animal which was developed by Kondo et al in 1957 and which was found to have a diabetic trait by Nakamura ${ }^{13)}$ in 1962 . We examined the heart of this animal. The $\mathrm{KK}$ mice were divided into 4 groups (1) Group KK-1 consisted of 7 animals of 4 weeks of age, the body weight being $16.5 \pm 1.2 \mathrm{~g}$. The fasting blood sugar was normal. (2) Group KK-2 consisted of 12 animals of 11-13 weeks of age, the body weight being $26.6 \pm 3.5 \mathrm{~g}$. The fasting blood sugar was $85.8 \pm 11.4 \mathrm{mg} / \mathrm{dl}$ and urine sugar was negative. (3) Group KK-3 consisted of 6 animals of $20-30$ weeks of age, the body weight being $41.0 \pm 1.6 \mathrm{~g}$. Their fasting blood sugar was $115.5 \pm 31.6 \mathrm{mg} / \mathrm{dl}$ and urine sugar was positive. (4) Group KK-4 consisted of 5 animals of 26-46 weeks of age, the body weight being $38.4 \pm 2.4 \mathrm{~g}$. Their fasting blood sugar was $190.6 \pm 16.1 \mathrm{mg} / \mathrm{dl}$ and urine sugar was positive. Results of light microscopic examinations are shown in table 1. Group KK-1 animals did not show any abnormal findings. Five out of 12 animals of group KK-2 showed myocardial degeneration and myocardial fibrosis. All animals of both KK-3 and KK-4 group showed histopathogical abnormalities including myocardial fibrosis, degeneration of remaining muscle cells and calcification of pericardium, interstitium and myocytes (Fig. 1). Electron microscopic examinations of the myocardium from the right ventricle of group KK-3 animals showed degeneration of myofibrils (Fig. 2), abnormality of $\mathrm{Z}$ bands, remnants of sarcoplasmic reticulum, destruction of the mitochondria, intramitochondrial glycogens and inclusion, convultions of nuclear membranes, crystalline inclusion in the cytoplasmic matrix, leptomeric fibrils, accumulation of myeline figures and increase of collagen fibers. There were no symptoms nor findings indicating myopathy of the skeletal muscles. No coronary artery change was observed. It seems reasonable to think that the myocardial alterations of the $\mathrm{KK}$ mice are not secondary to diabetes mellitus because the former was observed in group KK-2 mice which did not have the latter yet. We think that the cardiac changes are probably intrinsic in the $\mathrm{KK}$ mice because the changes were found in all animals of groups KK-3 and KK-4 examined. Therefore, the KK mice could be a disease model of spontaneous cardiompopathy.

A few attention have been drawn to the atrial invlovement in idiopathic cardiomyopathy. We have examined 11 patients with sick sinus syndrome to determine the nature 


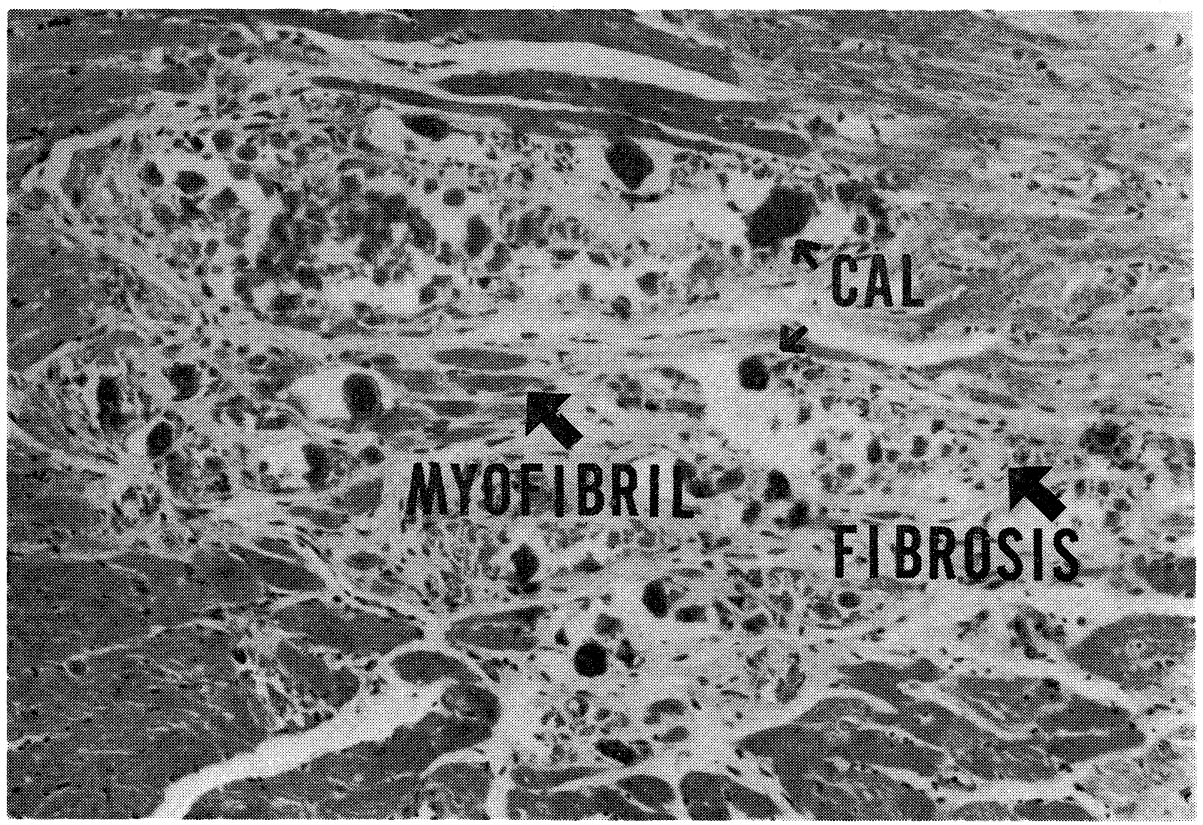

Fig. 1. A light micrograph of the right ventricular myocardium of a KK mouse aged 20 weeks. Degeneration of muscle fibers, myocardial fibrosis and calcium deposits (CAL) are observed. (Hematoxylin and eosin stain, $\times 400$ )



Fig. 2. An electron microgragh showing degeneration of myocyte. The myocyte in the middle shows degeneration of myofibrils and mitochondria and remnants of sarcoplasmic reticulum. Basement membrane of a capillary is not thickened. 
of the underlying heart disease. By employing non-invasive as well as invasive techniquesincluding coronary angiography and endomyo cardial biopsy, four out of 11 patients were found to have idiopathic cardiomyopathy ${ }^{14)}$. The predominant clinical symptoms were those of sick sinus syndrome. Endomyocardial biopsy of the right ventricle revealed myocardial degeneration with or without myocardial fibrosis. Biopsy of the left atrium performed at the surgery of implantation of the myocardial electrode showed extensive fibrosis of the atrial muscle. $\mathrm{We}^{15)}$ have also experienced three patients with persistent atrial standstill due to atrial inexcitability who were diagnosed to have idiopathic cardiomyopathy. Endomyocardial biopsy of the right ventricle revealed myocardial degeneration with or without myocardial fibrosis. Biopsy of the right atrium showed extensive myocardial fibrosis in one patient. Therefore, the atrial involvement of idiopathic cardiomyopathy may manifest itself as sick sinus syndrome when the involvement is limited, or as persistent atrial standstill when the involvement is extensive.

\section{SUMMARY}

(1) Familial cardiomyopathy has a veriety of clinical and pathological features. (2) Genetic factor may play an important role in the etiology of idiopathic cardiomyopathy. (3) KK mice could be a disease model of idiopathic cardiomyopathy. (4) Atrial involvement in idiopathic cardiomyopathy may manifest itself as sick sinus syndrome or persistent atrial standstill.

\section{REFERENCES}

1) Evans W: Familial cardiomegaly. Brit Heart J 11 : 68, 1949.

2) Rywlin AM, Barold SS, Linhart JW, Kramer HC, Meitus ML, Samet P: Idiopathic familial cardiopathy. A study of two families. J Génét hum 17: 453, 1969.

3) Kariv I, Kreisler B, Sherf L, Feldman S, Rosenthal T: Familial cardiomypathy. A review of 11 families. Am J Cardiol 28:
693, 1971

4) Sarachek NS, Leonard JJ: Familial heart block and sinus bradycardia. Classification and natural history. Am J Cardiol 29: 451, 1972.

5) Husson GS, Blackman MS, Rogers MC, Bharti S, Lev $\mathrm{M}$ : Familial congenital bundle branch system disease. Am J Cardiol 32 : 365, 1973 .

6) Williams DO, Jones EL, Nagle RE, Smith BS: Familial atrial cardiomyopathy with heart block. Quart J Medicine 41 : 491, 1972.

7) Battersby EJ, Glennar GG: Familial cardiomyopathy. Am J Medicine, 30: 382, 1961.

8) Emannuel R, Withers R, O'Brien K: Dominant and recessive modes of inheritance in idiopathic cardiomyopathy. Lancet II : 1065, 1971.

9) Clark GE, Henry WL, Epstein SE: FamiliaI prevalence and genetic transmission of idiopathic hypertrophic subaortic stenosis. N Engl J Med 289: 709, 1973.

10) Yamaguchi $M$, Toshima $H$, Yanase $T$, Ikeda H, Koga Y, Yoshioka H, Ito M, Fujino T, Yasuda H: A family study of idiopathic cardiomyopathy. Proc Japan Acad 53: 209, 1977.

11) Nishi S, Tanaka H, Shinyashiki T, Kanehisa $\mathrm{T}$ : Histopathological studies of the myocardium in the spontaneously cardiopathic $\mathrm{KK}$ mice: A new disease model of idiopathic cardiomyopathy. Abstracts of papers. VI Asian-Pacific congress of Cardiology 1976. p 84

12) Nishi S: A study on amimal model for cardiomyopathy: Histopathological investigations of the heart in $\mathrm{KK}$ mice and dystrophic mice. J Clin Electron Microscopy 10 : 77, 1977. (in Japanese with English abstracts)

13) Nakamura $M$ : A diabetic strain of the mouse. Proc Jap Acad 38: 348, 1962.

14) Toyama $Y$, Tanaka $H$, Kashima $T$, Uemura $\mathrm{N}$, Nuruki K, Nishi S, Katanazako H, Shinyashiki T, Mihara K, Kanehisa $\mathrm{T}$ : Idiopathic cardiomyopathy associated with the sick sinus syndrome. Jap Circ J 40: 513, 1976. (abstract)

15) Tanaka H, Atsuchi $Y$, Tanaka N, Nishi S, Kanehisa T, Tanaka S, Taira A: Persistent atrial standstill due to atrial inexcitability. An electrophysiological and histological study. Jap Heart J 16: 639, 1975. 